\title{
Histomorphological Spectrum of Diseases in Endobronchial Biopsy
}

\author{
Shrestha $R^{1}$, Shrestha $A^{2}$, Yogi $S^{3}$
}

\begin{abstract}
Key words: Endobroncial biopsy, Lung cancer, Tuberculosis

1. Dr. Richa Shrestha

2. Dr. Anil Shrestha

3. Dr. Subash Yogi

Address for Correspondence:

Dr. Richa Shrestha

Department of Pathology

Nepalgunj medical College Teaching Hospital

Kohalpur, Banke, Nepal

Email: shrestharicha@hotmail.com
\end{abstract}

Aim: To study the histomorphological pattern of disease in endobronchial biopsy in Nepalgunj Medical College Teaching Hospital (NGMCTH), Kohalpur.Background: Study of endobronchial biopsy is mainly indicated for malignancies, however, various other conditions including inflammatory pathology can be correctly identified.Material And Methods: This is a hospital based descriptive study carried out at Department of Pathology, NGMC, Kohalpur from August 2017 to July 2018. The study included 51 cases of endobronchial biopsy. All bronchial biopsies were processed according to the standard method and the detail microscopic findings were studied and the data were analysed statistically. Result: The age of patients ranged from 20-80 years. Cough was the most common presenting symptom. Most common benign pathology was tuberculosis and among malignancies squamous cell carcinoma was common histopathologicaldiagnosis.Conclusion: Identification of lung pathology at early stage with correct histological morophology is important to decrease morbidity and mortality related to both benign and malignant condition.

\section{INTRODUCTION}

Endobronchial biopsy is obtained via bronchoscopy passed through the nose or mouth to visualize the upper airway, identify any changes or lesion and collect pieces of lung tissue which allows assessment of various diseases including infectious, benign and malignant.

Lung cancer is currently the most frequently diagnosed cancer in the world and the most common cause of cancer mortality worldwide, comprising $17 \%$ of total new cases in male and $23 \%$ in female ${ }^{1}$.

The important indication for bronchial biopsy is the identification of bronchial malignancy, however, various other lesions including inflammation can be identified.

\section{MATERIAL AND METHODS}

This is a hospital based descriptive study carried out at Department of Pathology, NGMC, Kohalpur from August 2017 to July 2018. The study included 51 cases of endobronchial biopsy. All bronchial biopsies were received in neutral buffered formalin, were processed as per standard procedure. 4-5um thick sections were cut on microtome and stained with Hematoxylin and Eosin (H\&E) stain and the slides were studied in details microscopically ${ }^{2}$. Special stains like Periodic Acid Schiff (PAS) and Ziehl-Neelsen (ZN) were used when needed.

Data were analyzed using standard statistical method including SPSS 20.0.

\section{RESULT}

Among 51 cases included in the study, 22 (43.14\%) were female and $29(56.86 \%)$ were male with $\mathrm{M}: \mathrm{F}$ ratio of $1.3: 1$ Table I. Age of the patient ranged from 20-84 years with mean age of 60.01 . The maximum number of patients were in the age group of $51-60$ years and 61-70 years (17 each; $33.33 \%)$ as shown in Table II. Cough was the most common presenting complaint in 17 cases (33.33\%) followed by hemoptysis and chest pain (Table III). Benign (non-malignant) cases, including inadequate samples were 13 in number, most common benign pathology was tuberculosis (7; 13.73\%). 3 cases were labeled inadequate/ unsatisfactory due to crushing artifact and presence of necrotic material only.

Most common indications of biopsy was suspicion of malignancy. 38 cases were malignant and most common malignancy was Squamous Cell Carcinoma (25; $49.02 \%)$ followed by Adecocarcinoma and Small cell carcinoma (5 cases each; $9.80 \%$ ) as shown in Table IV. The correlation between clinical and histopathological diagnosis were done andwas roughly categorized as benign or malignant and was statistically significant with a P value of $<0.05$ (Table V). Growth/

mass on imaging was most common indication for biopsy followed by mucosal irregularity and erosion with necrotic plug. Out of 40 suspected malignant cases clinically, 32 were positive for malignancy and 8 was categorized as benign condition including inadequate sampling. 


\begin{tabular}{|c|c|c|}
\hline Sex & Frequency & $\%$ \\
\hline F & 22 & $43.14 \%$ \\
\hline M & 29 & $56.86 \%$ \\
\hline Grand Total & 51 & $100.00 \%$ \\
\hline
\end{tabular}

Table I: Sex Distribution

\begin{tabular}{|c|c|c|}
\hline Age group (Year) & Frequency & $\%$ \\
\hline $20-30$ & 4 & $7.84 \%$ \\
\hline $40-50$ & 4 & $7.84 \%$ \\
\hline $51-60$ & 17 & $33.33 \%$ \\
\hline $61-70$ & 17 & $33.33 \%$ \\
\hline $71-80$ & 7 & $13.73 \%$ \\
\hline$>80$ & 2 & $3.93 \%$ \\
\hline Grand Total & $\mathbf{5 1}$ & $\mathbf{1 0 0 . 0 0 \%}$ \\
\hline
\end{tabular}

Table II: Age group

\begin{tabular}{|c|c|c|}
\hline $\begin{array}{c}\text { Clinical } \\
\text { Presentation }\end{array}$ & Frequency & $\%$ \\
\hline Chest pain & 14 & $27.45 \%$ \\
\hline Cough & 17 & $33.33 \%$ \\
\hline Fever & 2 & $3.93 \%$ \\
\hline Hemoptysis & 18 & $35.29 \%$ \\
\hline Grand Total & $\mathbf{5 1}$ & $\mathbf{1 0 0 . 0 0 \%}$ \\
\hline
\end{tabular}

Table III: Clinical Presentation

\begin{tabular}{|c|c|c|}
\hline Histopathological Diagnosis & Frequency & $\%$ \\
\hline Adenocarcinoma & 5 & $9.80 \%$ \\
\hline Amyloidosis & 1 & $1.96 \%$ \\
\hline Fungal-aspergillus & 1 & $1.96 \%$ \\
\hline Idiopathic pulmonary fibrosis & 1 & $1.96 \%$ \\
\hline Inadequate & 3 & $5.88 \%$ \\
\hline Small cell carcinoma & 5 & $9.80 \%$ \\
\hline Squamous cell carcinoma & 25 & $49.02 \%$ \\
\hline Tuberculosis & 7 & $13.73 \%$ \\
\hline Undifferentiated carcinoma & 3 & $5.89 \%$ \\
\hline Grand Total & 51 & $100.00 \%$ \\
\hline
\end{tabular}

Table IV: Histopathological diagnosis

\begin{tabular}{|c|c|c|c|c|c|}
\hline \multicolumn{4}{|c|}{ Histological Categorization } & Total & \\
\hline Malignant & benign & malignant & unsatisfactory & & \\
\hline Clinical diagnosis & 6 & 32 & 2 & 40 & 노 \\
\hline \multirow[t]{2}{*}{ Tuberculosis } & 4 & 6 & 1 & 11 & $\frac{\frac{2}{2}}{\frac{2}{2}}$ \\
\hline & 10 & 38 & 3 & 51 & $a$ \\
\hline
\end{tabular}

Table V: Clinical diagniosis and Histological categorization Crosstabulation

\section{DISCUSSION}

Lung cancer is one of the leading case of cancer related deaths in men and women. The increasing number of deaths is mainly due to its detection at the late stage ${ }^{3}$. Thus, timely detection and management is important for long term survival of the patients. Bronchial biopsy and histopathology is a valuable tool in diagnosis of lung disease, both benign and malignant.

According to the latest World Health Organization (WHO) data published in 2017, lung disease death in Nepal reached $11.81 \%$ of total death and Nepal ranks $2^{\text {nd }}$ number in the world ${ }^{4}$. In fiscal year $2074 / 75$, a total of 32,474 cases of TB was notified and registered. Among the notified cases $71 \%$ of all TB cases were pulmonary TB and Terai belt reported more than half of the cases $(57 \%)$. In Province 5 alone 7036 cases were noted with highest notification rate $^{5}$ Bronchial biopsy is performed through flexible fiberoptic bronchoscopy and tissue is submitted for histopathological examination. The drawback of this procedure is that the tissue may get crushed creating artifactual changes and difficulty during histopathological examination as well as the peripheral lesion may be missed ${ }^{6}$. It is important to know the true histological cell type in cases of primary lung cancer as it influences the management and allow prediction of prognosis.

Males were more involved by lung disease with $M: F$ ratio of 1.3:1 which is similar to study done by Bhat et al, Fuladi et al and Bodh et $a^{1,7,8}$. Cough was the most common presenting symptom, followed by hemoptysis and chest pain which is similar to study done by Okugbo SV ${ }^{6}$.

Most common benign lesion in this study was Tuberculosis, similar to Okugbo SV study ${ }^{6}$.

Among malignancies, SCC was the most common finding similar to Bhat et al, Rajasekaran et al and Gupta et al, followed by Small cell carcinoma and Adenocarcinoma similar to other writers ${ }^{1,9,10}$.

\section{CONCLUSION}

Identification of lung lesion at early stage is important to decrease mortality and morbidity. Infectious disease like tuberculosis can be treated with correct diagnosis. Malignancy with correct

histopathological typing can have correct management plan. Only drawback of endobronchial biopsy is inadequate sample or artifactual changes.

\section{REFERENCES}

1. Bhat N, Nazeer MJ, Bashir N, Farooq S, Fatima K, Baba KM. Correlation of bronchial biopsy with bronchoalveolar lavage in lung malignancies. Int J Res Med Sci. 2016 Feb;4(2):428-435.

2. Bancroft DJ. Theory and Practices of Histological Techniques. 7th ed. India: Elsevier; 2013. p 105-123.

3. Koss LG, Melamed MR. Koss Diagnostic Cytologty and its histopathological bases Vol II. 5th ed America: Lippincot 2006; 919-48.

4. WHO World health ranking/Nepal; 2017. Available from: http:// www.worldlifeexpectancy/worldhealthranking/Nepal. 
5. Annual report; 2074/75 (2017/18) Department of Health service, Nepal.

6. Okugbo SU, Ugiagbe EE. Outcome of bronchoscopic biopsies in the University of Benin Teaching Hospital. Nijer Med J. 2013; 54(3): 157-159.

7. Fuladi AB, Munje RP, Tayade BO. Value of Washings, Brushings, and Biopsy at Fibreoptic Bronchoscopy in the Diagnosis of Lung Caner. JIACM. 2004;5(2):137-42.

8. Bodh A, Kaushal V, Kashyap S, Gulati A. Cytohistological correlation in diagnosis of lung tumors by using fiberoptic bronchoscopy: Study of 200 cases. Indian J Pathol Microbiol. 2013;56:84-8

9. Rajeskaran S, Manickam TG, Visanthan PJ, Jayachandran CS, Subbaraman R, Bhanumathy $V$, et al. Pattern of primary lung cancer: A Madras study. Lung India. 1993;11(1,2):7-11.

10. Gupta D, Boffeta P, Jindal GV, Vaccarella SK, Herrero S, Nandakumar R, A Risk factors of lung cancer in Chandigarh, India. Ind J Med Res. 2001;113:142-50. 